\title{
EL HORNO ROMANO DE O REDOLLIÑO (CANGAS, PONTEVEDRA) ${ }^{1}$
}

\section{THE ROMAN OVEN OF O REDOLLIÑO (CANGAS, PONTEVEDRA)}

\author{
ROBERTO ABOAL FERNÁNDEZ ** \\ VIRGINIA CASTRO HIERRO ** \\ RAFAEL RODRÍGUEZ MARTÍNEZ **** \\ Laboratorio de Arqueoloxía da Paisaxe, Instituto de Estudos Galegos Padre Sarmiento (CSIC-XuGa) \\ Unidade Asociada: Laboratorio de Paleoambiente, Patrimonio e Paisaxe (IIT, USC)
}

\section{Resumen}

En este texto se muestran los resultados de la excavación de un horno cerámico de material de construcción de época romana, situado en el ayuntamiento de Cangas, descubierto durante las obras de construcción del Corredor do Morrazo. Se presentan las evidencias arqueológicas documentadas, limitándose éstas a los restos aislados del mencionado horno, así como las conclusiones obtenidas tras los trabajos de excavación.

\section{Palabras clave}

Impacto arqueológico, seguimiento arqueológico, medidas correctoras, período romano, horno cerámico, excavación estratigráfica.

\begin{abstract}
This paper shows the results of the excavation of a Roman kiln for building materials, located in the municipality of Cangas. The kiln was discovered during the archaeological assessment of the Morrazo motorway works. The archaeological evidences documented are limited to the isolated remains of the kiln.
\end{abstract}

\section{Keywords}

Archaeological impact, watching brief, corrective measures, Roman period, ceramic kiln, stratigraphic excavation.

1 Este trabajo fue entregado a la revista el 10 de marzo de 2008.

** Laboratorio de Patrimonio, Paleoambiente e Paisaxe (IIT, USC). Unidad asociada al CSIC a través del Instituto de Estudios Gallegos Padre Sarmiento.

Este artículo ha sido realizado en colaboración con Anxo Rodríguez Paz, del Laboratorio de Arqueoloxía da Paisaxe del IEGPS, como autor del apartado gráfico.

*** Arqueólogo de la Excma. Diputación de Pontevedra. 


\section{INTRODUCCIÓN.}

La intervención arqueológica desarrollada en el yacimiento de O Redolliño (Cangas, Pontevedra) se enmarca dentro del programa de Corrección de Impacto Arqueológico de la construcción del Corredor do Morrazo (Criado y Cabrejas 2005). Las medidas correctoras adoptadas, la realización del seguimiento arqueológico, así como los trabajos de excavación fueron llevados a cabo a por el Laboratorio de Arqueoloxía da Paisaxe del Instituto de Estudos Galegos Padre Sarmiento (CSIC-XuGa), y su Unidad Asociada, el Laboratorio de Patrimonio, Paleoambiente e Paisaxe (IIT, USC).

La excavación fue realizada entre los meses de agosto y septiembre de 2003 en el Tramo II-2 Cangas-Bueu, construido por la empresa Morrazo UTE (OHL-Malvar).

El Corredor do Morrazo tiene una longitud total de 20,96 Km y presenta un trazado general E-W que transita por el sector meridional de la Península de O Morrazo, concretamente por los ayuntamientos de Moaña, Cangas y Bueu. La obra parte

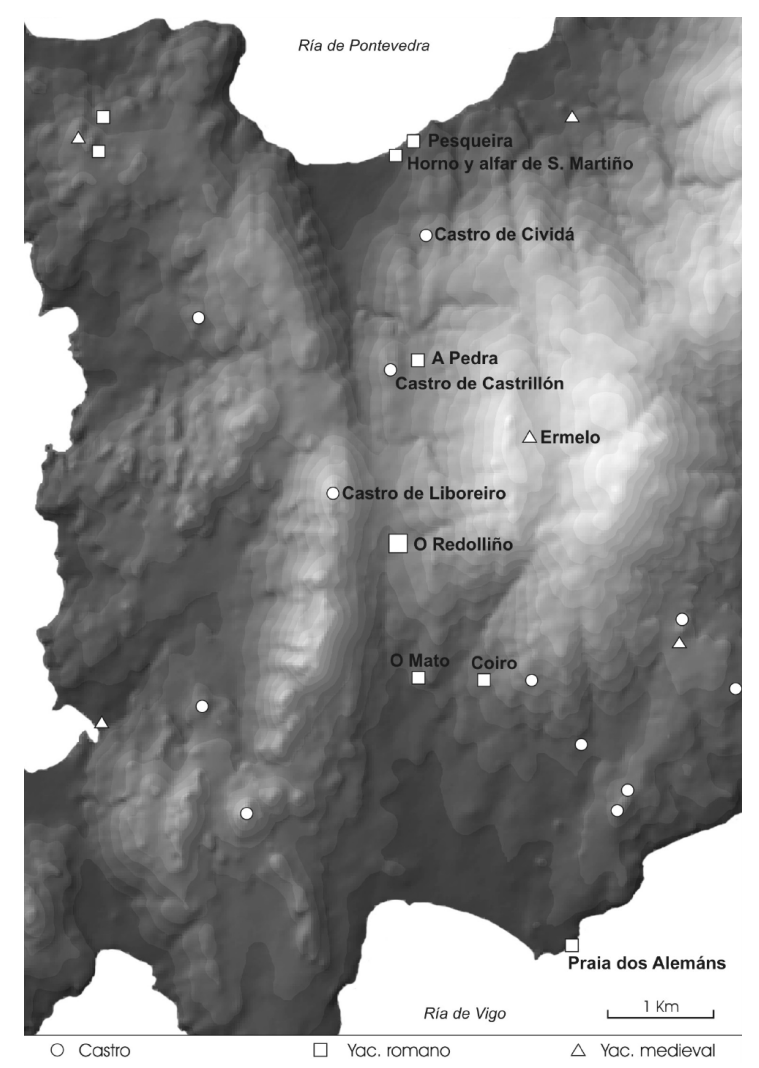

Figura 1: Mapa de situación con la localización de los yacimientos. 
del enlace con la autopista A-9 y termina en la comarcal 550, al norte del ayuntamiento de Cangas (Criado y Cabrejas 2005).

La zona de $O$ Redolliño se localiza en el tramo final de ladera, a unos $135 \mathrm{~m}$ de altitud, en un collado con orientación N-S que comunica las localidades de Bueu y Cangas (esta fractura -A Portela- actúa claramente como vía natural de tránsito). La zona se encuentra por lo tanto encajada a este y oeste por los montes de Carballal y Os Laguiños y por el Outeiro Agudo y Monte Liboreiro respectivamente, mientras que se abre hacia el $\mathrm{N}$ y S divisando parcialmente la ensenada de Cangas.

En relación con el entorno arqueológico destaca sin duda la ubicación del Castro de Liboreiro, situado a unos $500 \mathrm{~m}$ al NW, en el alto más destacado. En el entorno más inmediato, además de petroglifos y mámoas, se localizan el yacimiento prehistórico de Os Laguiños, el castro de Castrillón, y los yacimientos romanos de O Mato y A Pedra (Figura 1).

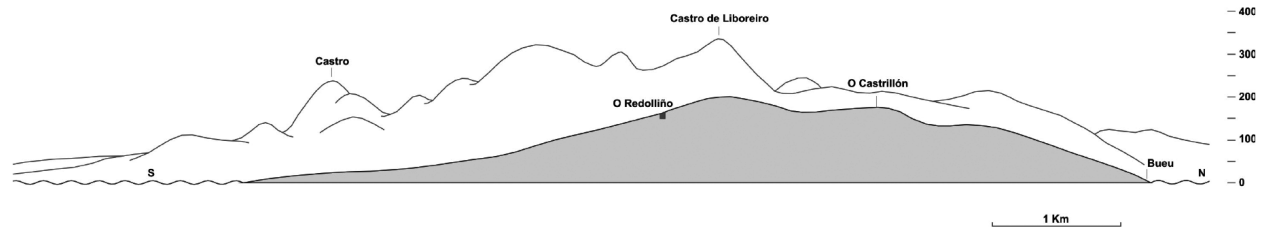

Figura 2: Perfil topográfico S-N del paso natural de A Portela y localización de algunos de los yacimientos arqueológicos del entorno.

\section{DEFINICIÓN Y VALORACIÓN DE LAS EVIDENCIAS DE PARTIDA.}

El yacimiento fue descubierto durante los trabajos de control y seguimiento arqueológico, durante los cuales se identificaron los restos de una estructura excavada en el sustrato mineral, abundante material constructivo (básicamente ladrillo) y varios conjuntos cerámicos de períodos diversos.

El hallazgo de estas evidencias dio lugar al establecimiento de un área de cautela y a la realización de una intervención arqueológica. La secuencia de los trabajos fue la siguiente:

- Dado que la estructura fue identificada en fase de obra, se procedió a la retirada con medios mecánicos del escombro generado por las palas excavadoras y a la limpieza manual del entorno inmediato de la estructura, con la finalidad de documentar nuevas evidencias. Los resultados proporcionados por esta limpieza permitieron identificar cinco nuevas estructuras igualmente excavadas en el horizonte mineral (tres de ellas lineales y dos de menores dimensiones, una de ellas cortada por una de las zanjas lineales de mayor tamaño y otra que aparecía de forma aislada). 
- Una vez limpia la superficie, se replanteo una malla de URs de 4 x 4 m que englobaba las evidencias identificadas (abarcando un total de $144 \mathrm{~m}^{2}$ ).

- Finalmente se procedió a la excavación de las estructuras. Los GERED0012, GERED004, GERED005 y GERED006 se excavaron en su totalidad, mientras que el GERED002 fue excavado en su tramo intermedio y el GERED003 únicamente fue cortado en dos tramos.
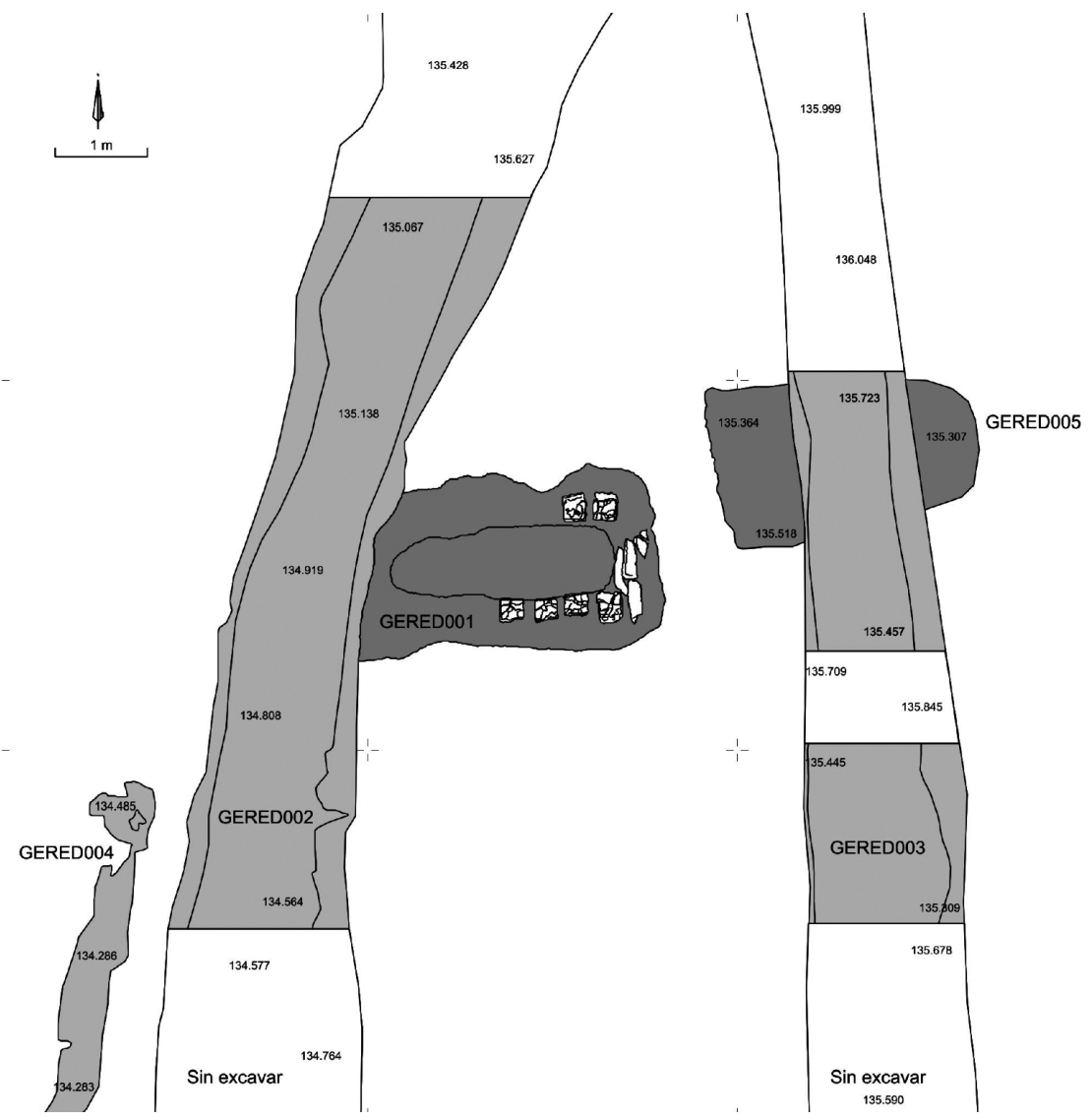

Figura 3: Planta de la excavación.

${ }^{2}$ Los códigos de GERED001... los usamos para referirnos a cada una de las estructuras documentadas. GE significa Grupo Estratigráfico (conjunto de Unidades Estratigráficas que forman parte de una estructura), RED se refieren al topónimo del yacimiento y finalmente el número según el orden de identificación. El mismo sistema es seguido para las Unidades Estratigráficas. Sobre el sistema de registro se puede consultar C. Parcero, F. Méndez y R. Blanco: El registro de la información en intervenciones arqueológicas. Col. CAPA, 9. Santiago de Compostela: LAFC, Universidade de Santiago. 1999. 


\section{RESULTADOS DE LA INTERVENCIÓN.}

Una vez excavadas las estructuras se comprobó que únicamente una de ellas era de naturaleza arqueológica, la GERED001.

Las GERED002, 003 y 004 eran unas zanjas lineales. Se trataba de estructuras, posiblemente de época moderna, vinculadas con sistemas de canalización y drenaje de aguas, relacionadas con el riego de los cultivos o con la construcción de las terrazas situadas en el entorno inmediato. Este extremo viene confirmado por la configuración de los depósitos que las colmataban (niveles de gravas que erosionaban la base de las mismas).

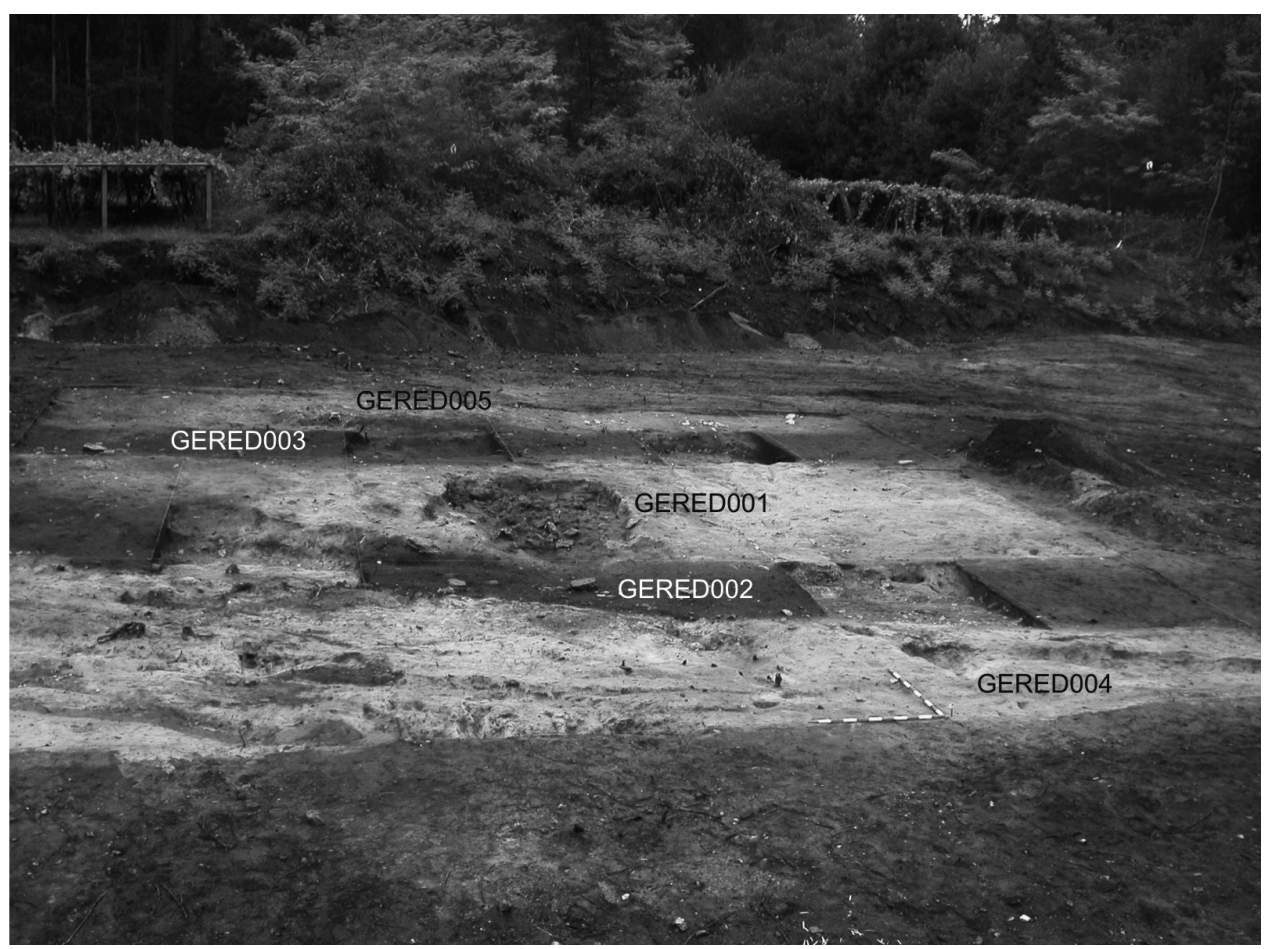

Figura 4: Vista general del área de excavación con las estructuras excavadas.

La GERED002 fue cortada en su tramo intermedio, aunque continúa fuera de los límites del área de excavación. Se encontraba colmatada por un depósito de tierra entremezclado con abundantes gravas y con presencia de cuarzos. Las paredes del corte son inclinadas y la base es plana. No se documentaron materiales arqueológicos en el interior. Tiene una longitud de 12,47 m (N-S), y una anchura que oscila entre 1,20 y 2,30 m. El trazado de esta zanja corta la estructura GERED001 por su lado W (Figura 8). 


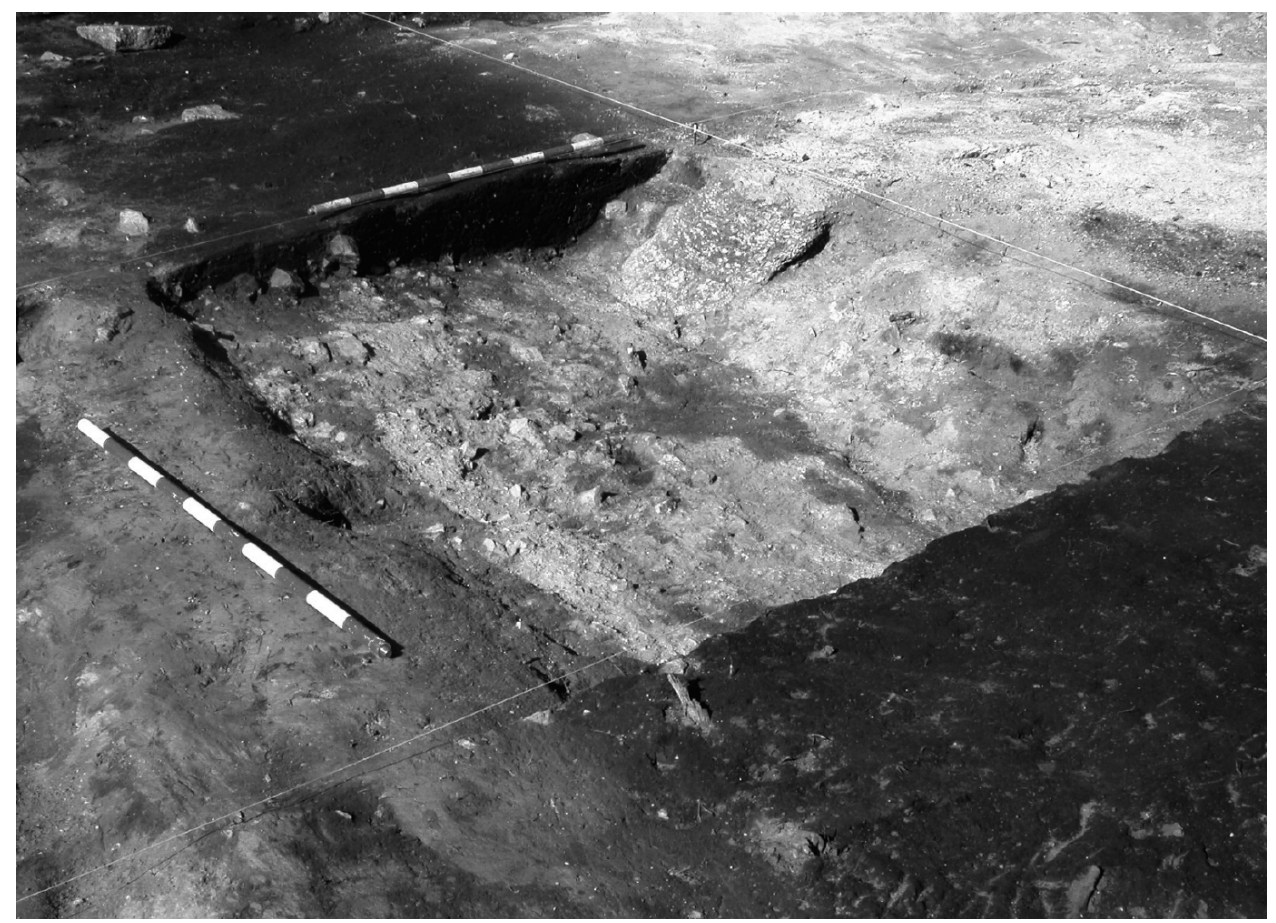

Figura 5: Detalle del corte de la GERED002.

La GERED003, fue cortada en dos tramos y, al igual que la anterior, continúa fuera de los límites de la excavación. Los depósitos que la colmataban eran de tierra arcillosa con abundancia de gravas y arenas, que se hacían más abundantes al llegar a la base de la estructura. Las paredes son inclinadas y la base plana. No se documentaron materiales arqueológicos en el interior de los depósitos. Sus dimensiones son 12,04 m de longitud y una anchura que oscila entre 1,24 y 1,87 m.

Como ya dijimos antes, esta zanja cortaba otra estructura anterior, la GERED005. Durante la excavación pudimos comprobar que la GERED003 alteró completamente la morfología y características de la GERED005, conservándose únicamente una parte pequeña de los extremos, que no permitieron precisar ni su adscripción tipológica ni cultural (tampoco se recuperaron materiales arqueológicos de ningún tipo en el interior de los depósitos).

La otra estructura lineal identificada, la GERED004 fue vaciada en su totalidad. Estaba colmatada por un depósito de tierra con gravilla y cuarzos más abundantes hacia la base. Sus paredes son ligeramente inclinadas y su base es completamente irregular, con numerosas intrusiones, hasta llegar a desaparecer por su extremo S; 


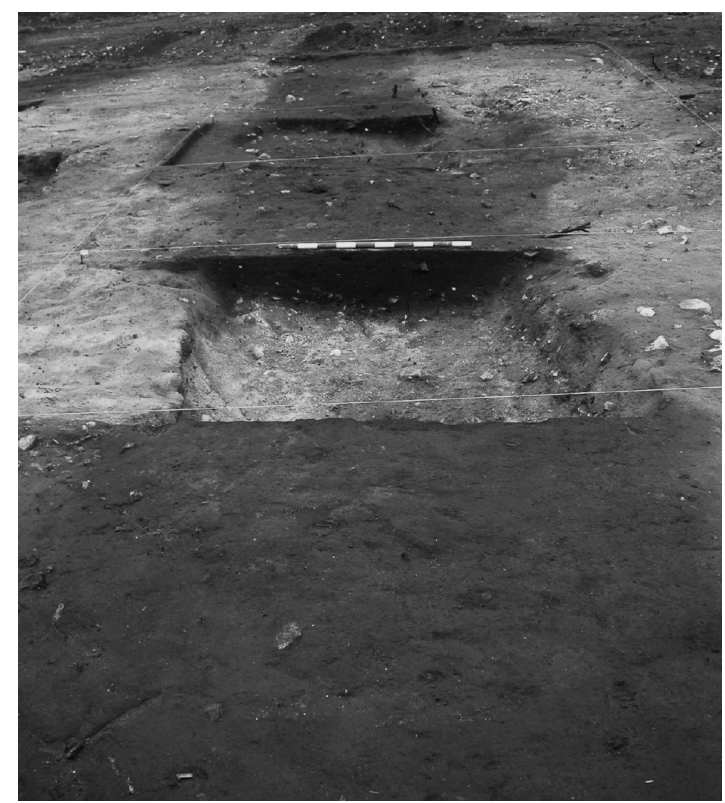

Figura 6: Vista de los cortes realizados al GERED003 y corte de la GERED005.

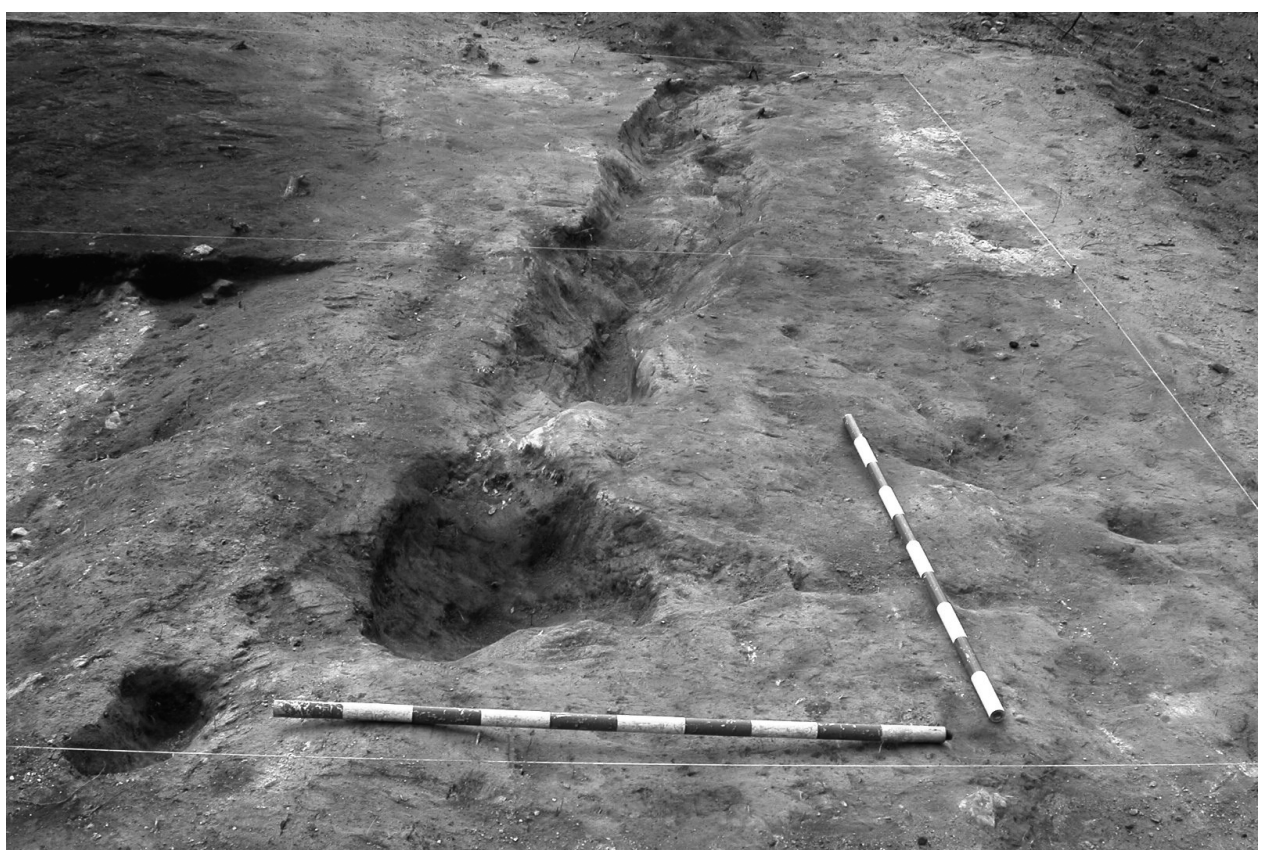

Figura 7: Vista del corte de la GERED004. 
por su lado $\mathrm{N}$ está alterada por una raíz de un árbol. No se recuperaron materiales en el interior. Su formación parece responder a un proceso natural provocado por la erosión generada por la circulación de agua.

Durante los trabajos se identificaron algunas posibles estructuras que, una vez excavadas, resultaron ser improntas de las palas excavadoras o raíces de árboles, por este motivo no las incluimos en la descripción (como es el caso de la GERED006).

Y finalmente la GERED001, que resultó ser la estructura más interesante de todo el conjunto. Una vez excavada, se confirmó que se trataba de los restos de un horno cerámico de material de construcción, de planta rectangular, del que únicamente se conservan los cimientos.

Esta estructura, como ya dijimos, se encontraba cortada por su lado W por la zanja lineal GERED002 y alterada por la pala excavadora, en la parte N. La estructura se encontraba colmatada por varios depósitos de tierra de diferentes características, pero todos ellos entremezclados con abundantes restos de material cerámico de construcción y pequeñas piedras de granito; que parecen responder a momen-

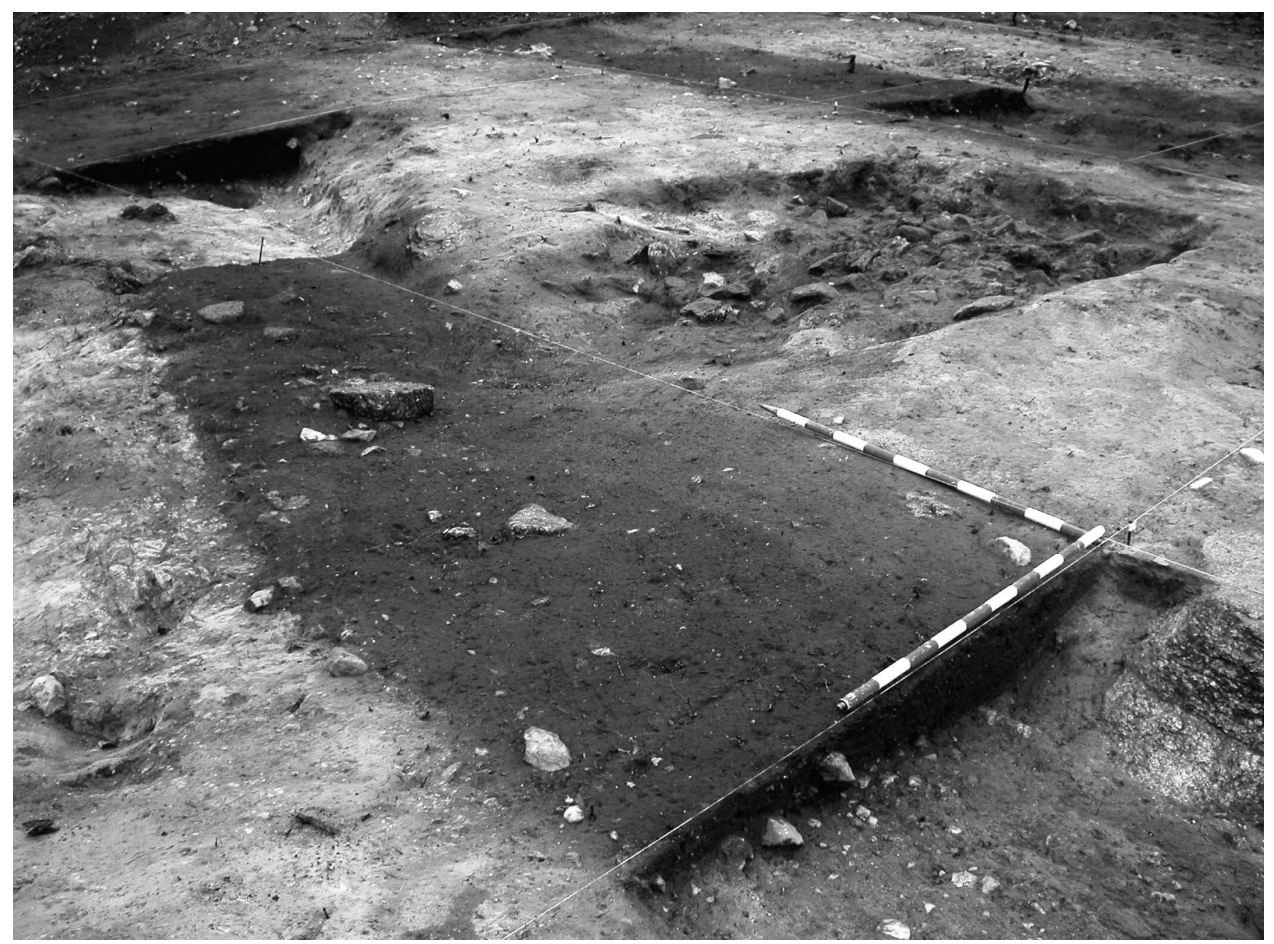

Figura 8: Detalle de la GERED002 cortando la GERED001. 


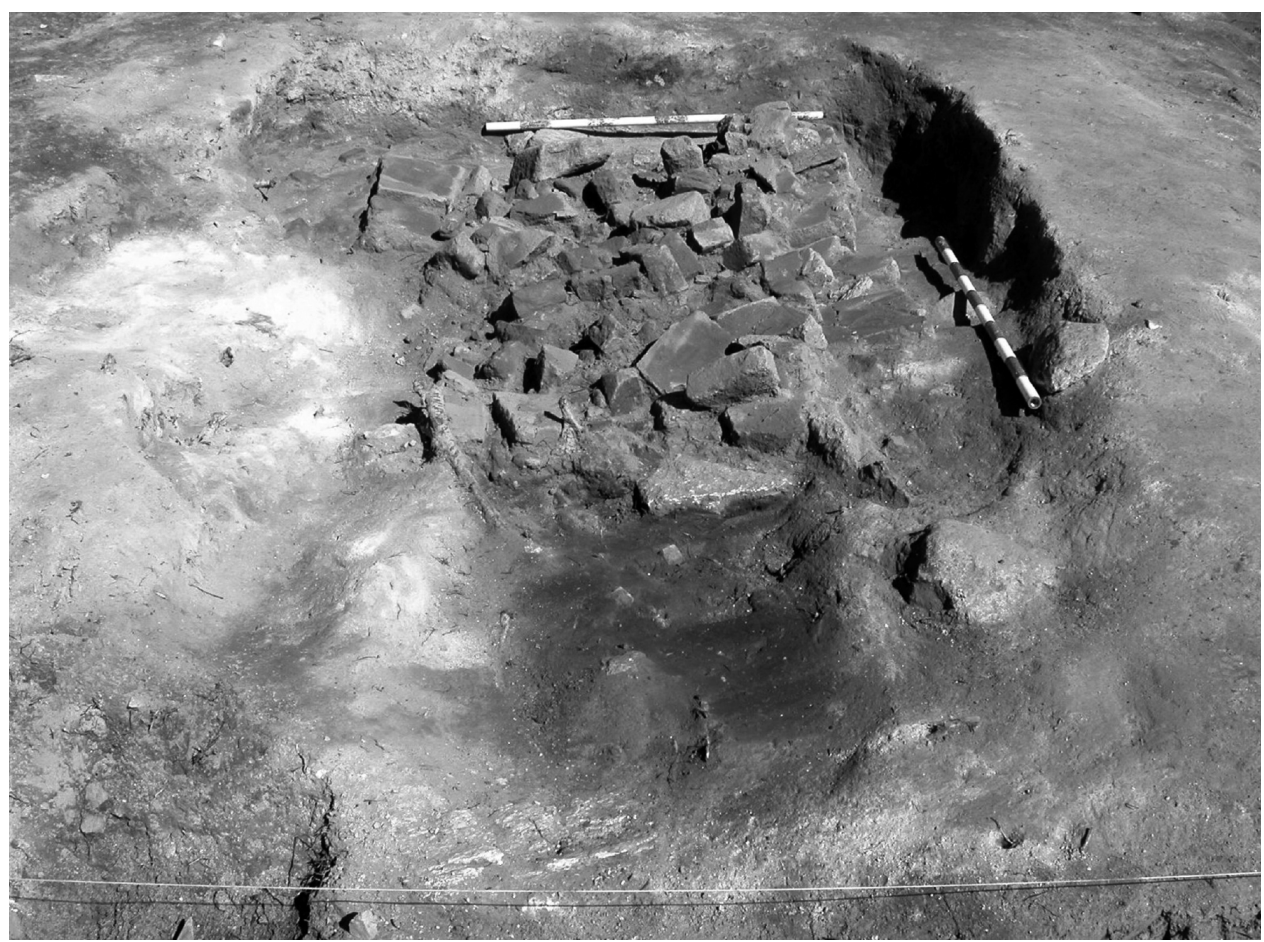

Figura 9: Vista del derrumbe UERED021.

tos de abandono y destrucción del horno cerámico (UERED010, UERED017 y UERED018).

Estos niveles sellaban un depósito compuesto por materiales constructivos, ladrillo y teja, que aparecen dispuestos en la parte central de la estructura, con menor presencia de tierra y con ladrillos de mayor tamaño y con un menor grado de rodamiento (UERED021). Se trata del derrumbe de los arcos y de la parrilla del horno. La disposición de este derrumbe parece indicarnos claramente que la estructura se hundió por la parte central.

Una vez levantados los diferentes niveles de abandono y de derrumbe se define la cámara de fuego, que está excavada en el sustrato mineral. Su forma en planta es rectangular y tiene unas dimensiones de 3,00 $\mathrm{m}$ de largo por 2,00 $\mathrm{m}$ de ancho (UERED030). En el interior de la cámara se identificaron parte de los cuatro arcos de sustentación de la parrilla (UERED022). Únicamente se conservaban los pies de seis de ellos (los otros coinciden en la zona alterada por la pala excavadora). Los arcos arrancan a $0,30 \mathrm{~m}$ de las paredes laterales de la cámara y están construidos con ladrillos. 


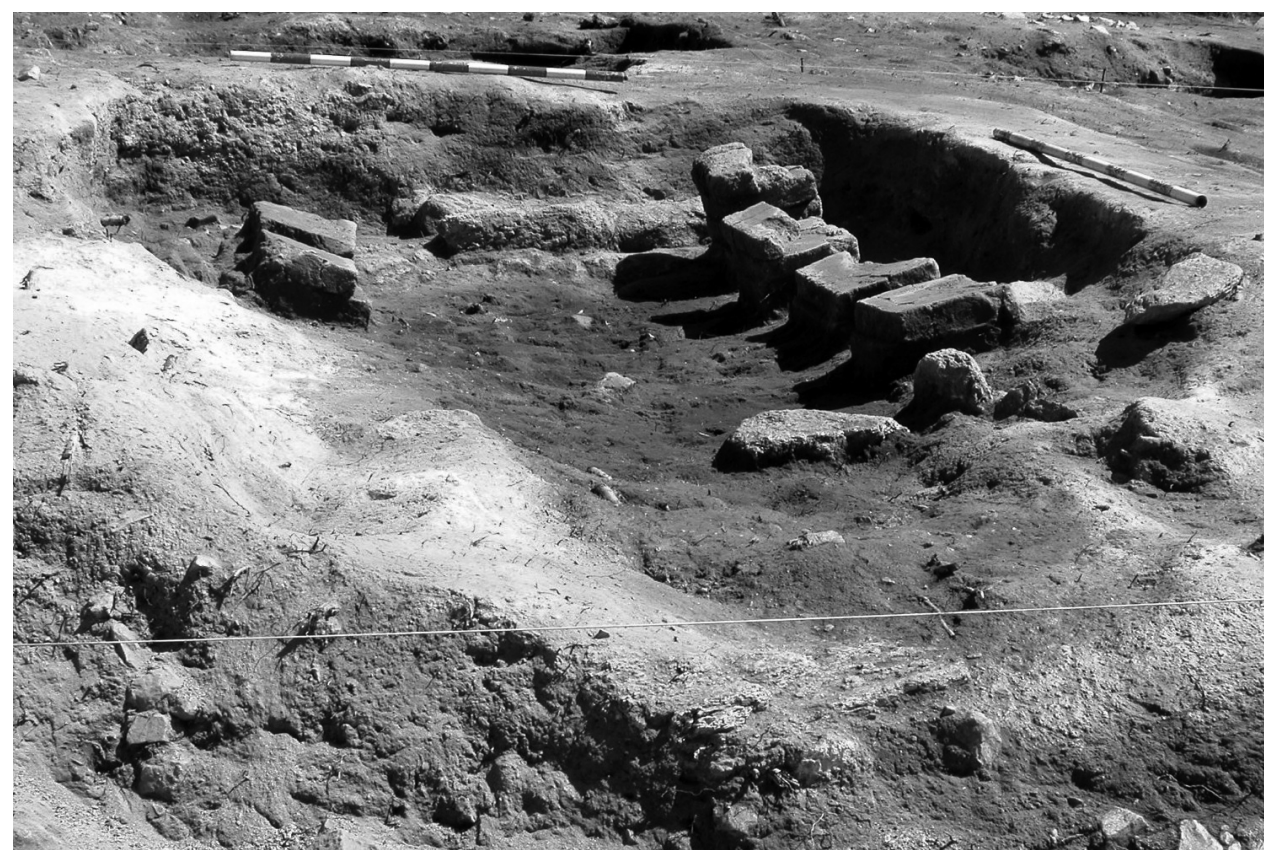

Figura 10: Vista de la UERED022 y UERED030.

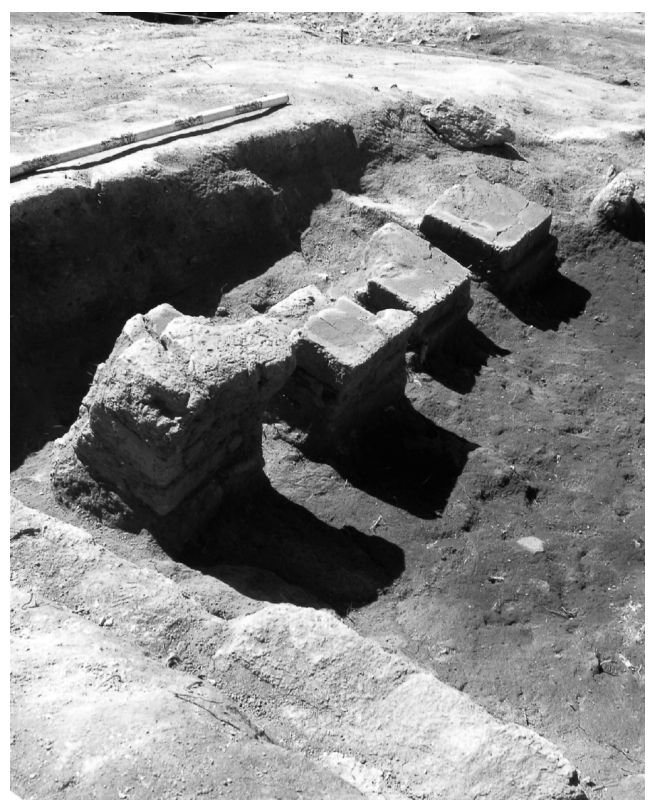

Figura 11: Detalle de parte de los arcos. 
Estos arcos se apoyan sobre una tierra arcillosa de color grisáceo (UERED029) que rellenaba el espacio entre éstos y las paredes de la cámara, a la vez que serviría de asiento en el sustrato.

La parte correspondiente al praefurnium no se conservaba, ya que fue destruida por una de las zanjas lineales (GERED002). Únicamente se conservan los restos de una tierra carbonizada (UERED023) que se extiende por el espacio definido entre los arcos, rellenando la parte central (ligeramente rebajada y que desciende suavemente en el sentido de la boca del horno). La mayor presencia de carbones en la parte baja, nos indican que nos encontramos en la zona en la que se prendía el fuego para la alimentación del horno.
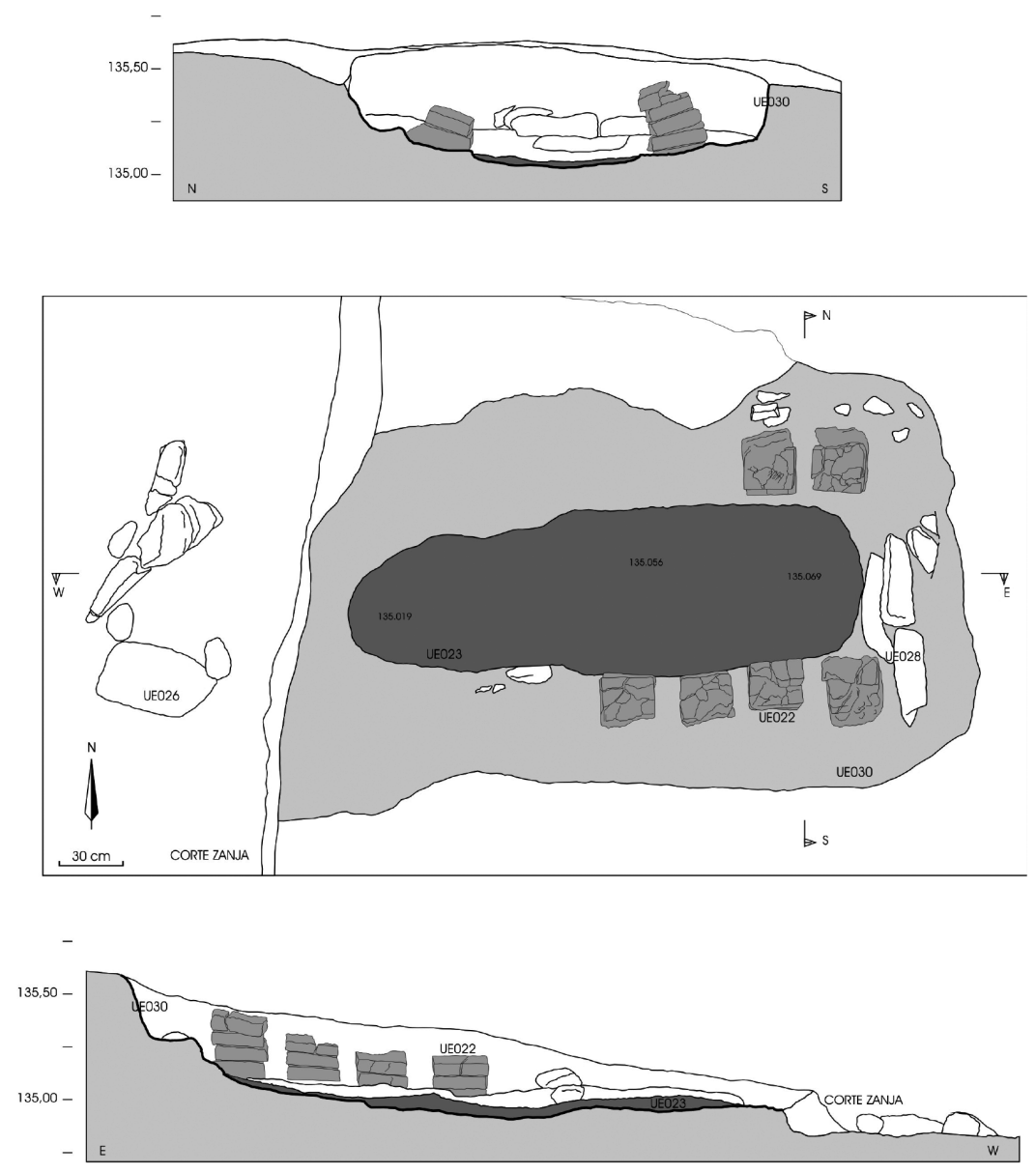

Figura 12: Planta y secciones del horno. 
De la cámara de cocción no se conservaba nada, por lo que no podemos definir ni la altura ni el tipo de cubierta que tendría. Tampoco se conservan restos del muro perimetral, únicamente se han identificado en el lado E de la cámara cinco piedras de granito de entre 0,35 y $0,40 \mathrm{~m}$ (UERED028) apoyadas sobre el sustrato y que desconocemos si pudieron haber formado parte del muro (son unas piedras que no presentan cara, ni muestran señales de estar trabajadas).

Por lo que se refiere a los materiales cerámicos, además del de construcción (ladrillo y teja), únicamente se documentaron cinco fragmentos de cerámica durante los trabajos (a pesar de que se había recuperado material diverso durante las labores de seguimiento).
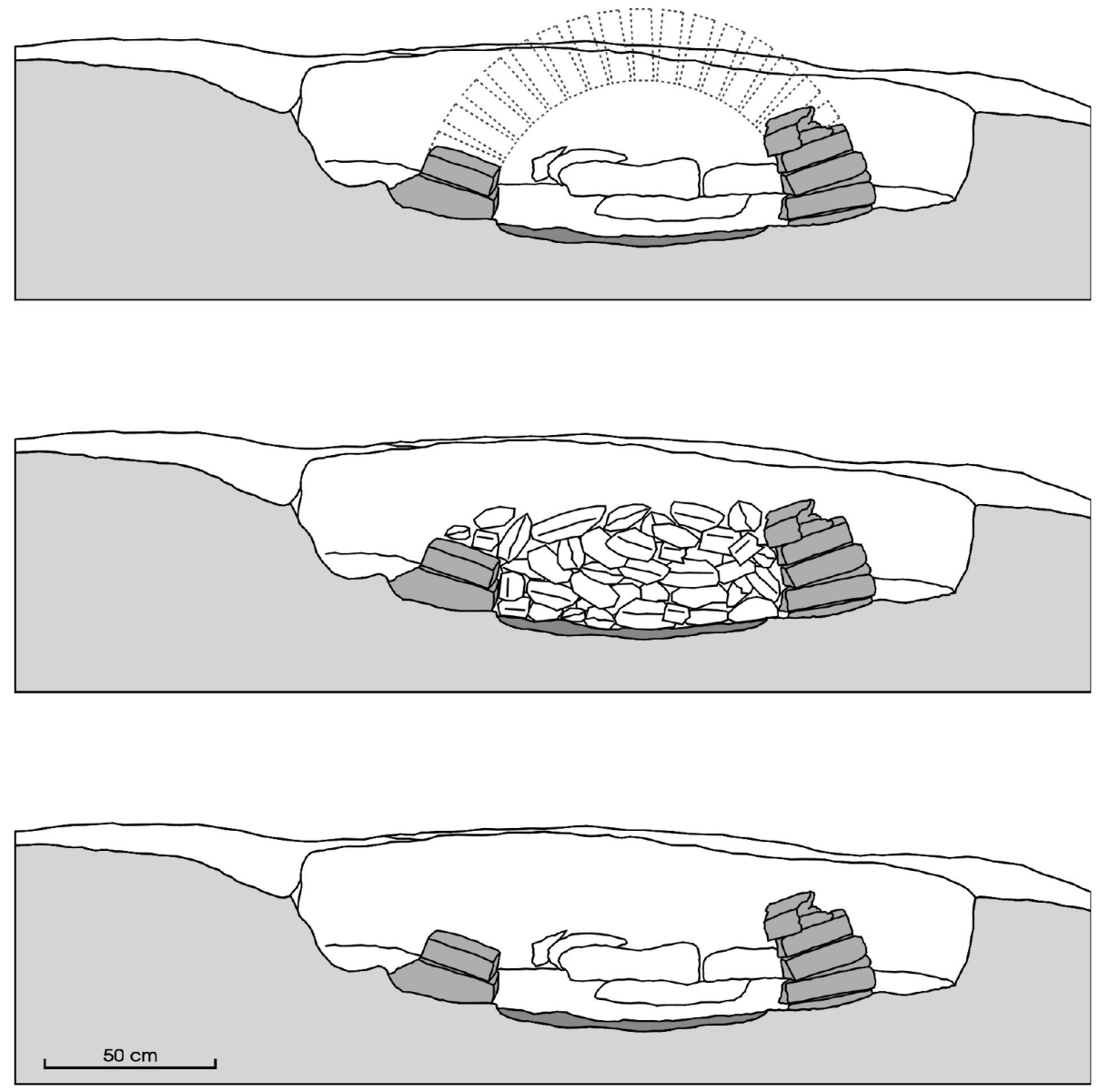

Figura 13: Reconstrucción hipotética del derrumbe de los arcos del horno. 


\section{ANÁLISIS DE LA CULTURA MATERIAL.}

La cultura material recuperada durante la excavación está compuesta de forma mayoritaria por material de construcción (ladrillo y teja). Las piezas que componen el citado conjunto son:

\section{Ladrillo}

Supone el $90 \%$ del total del conjunto. Se trata en su totalidad de ladrillos muy similares, por lo que a dimensiones se refiere, a los denominados bessalis, aunque su adscripción a dicho tipo resulta dudosa pues se documentaron conformando los arcos en los que se apoyaría la parrilla del horno. Las dimensiones de los ladrillos recuperados son homogéneas $(0,25 \times 0,21 \times 0,05 \mathrm{~m})$; presentando una pasta naranja de tipo micáceo, con algún elemento de cuarzo como desgrasante.
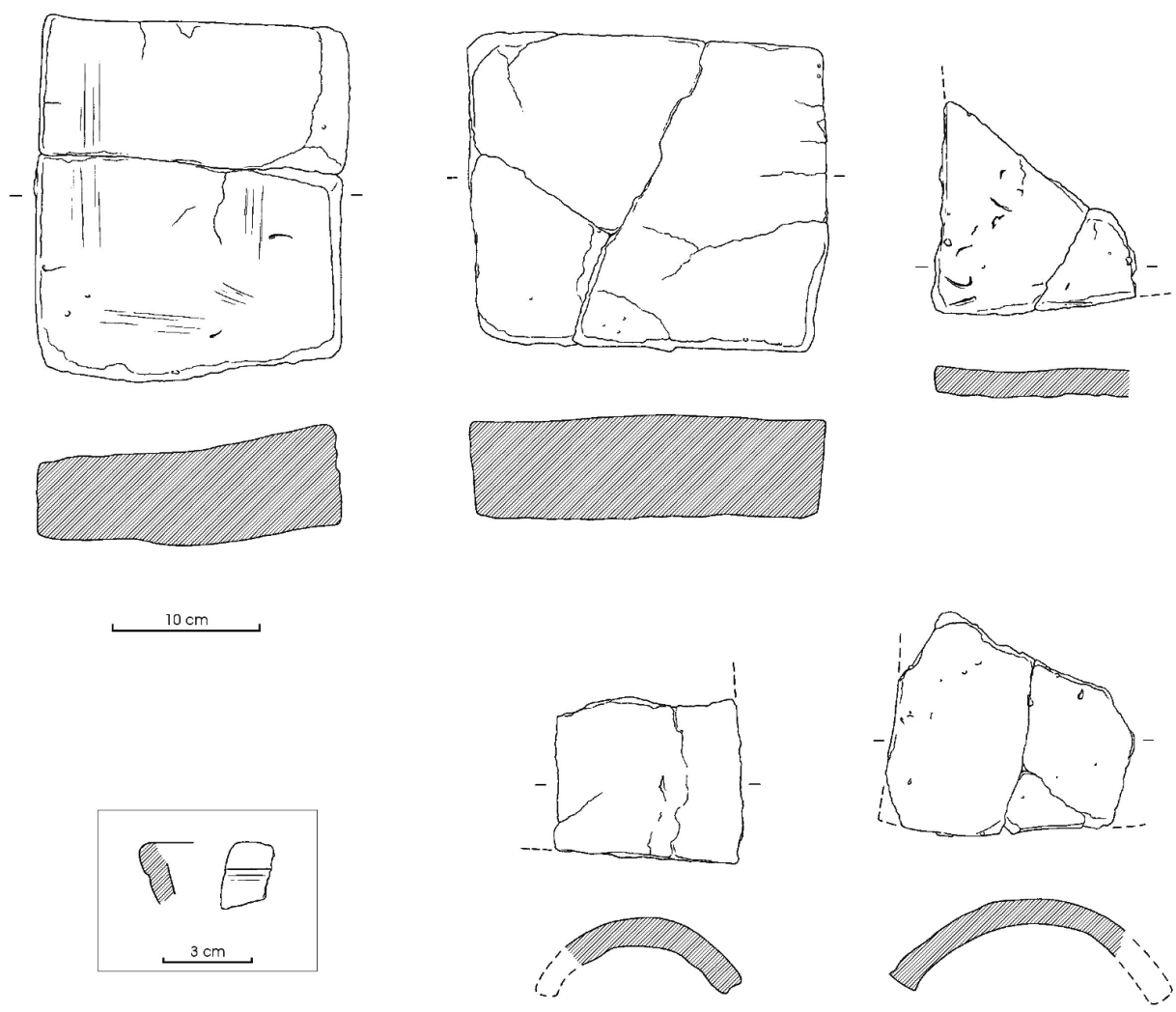

Figura 14: Dibujo de los materiales recuperados durante los trabajos de excavación (ladrillos de los arcos y fragmentos de teja) y del único borde recuperado. 
Tanto por la homogeneidad de las dimensiones, como por la propia finalidad desempeñada por las piezas, podrían encuadrarse cronológicamente los materiales en época romana, posiblemente tardía (III-V d. C.) tal y como indica el grosor de los ladrillos ${ }^{3}$.

\section{Teja}

El otro elemento mayoritario del conjunto cerámico exhumado. Se trata de ímbrices de cierto tamaño, de pasta anaranjada, micácea y con desgrasante granítico. Presentan un buen remate (algunas piezas tienen las superficies alisadas). Desde el punto de vista cronológico no puede aportarse ningún dato, pues se trata de un elemento de enorme pervivencia.

\section{Indeterminado}

Bajo este epígrafe recogemos varios fragmentos cerámicos de sección semicircular que tienen la superficie totalmente quemada. Atendiendo a los elementos que caracterizan estos fragmentos, parece evidente que nos encontramos ante los restos de la parrilla del horno.

\section{Cerámica común}

Se recuperaron cinco fragmentos, cuatro galbos y un borde. En el caso de los galbos, su estado deteriorado hace imposible cualquier tipo de adscripción cronológico-cultural y, en el caso del borde, se trata de un tipo cerámico que se documenta en época romana, pero que perdura hasta nuestros días.

Fragmento de un cuenco de pastas rojizas bien decantadas, caracterizado por presentar una pequeña incisión en la pared exterior marcando el tránsito del galbo al borde, la dureza de su pasta nos indica que fue objeto de una cocción prolongada a altas temperaturas, lo que a su vez es indicio de un importante control del fuego y de las técnicas de control de cocción.

\section{VALORACIÓN ARQUEOLÓGICA DE LA INTERVENCIÓN.}

Los resultados proporcionados por los trabajos de excavación, nos indican claramente que nos encontramos ante un horno cerámico de material de construcción de época romana.

\footnotetext{
${ }^{3}$ Los ladrillos con un grosor de 0,05 m se documentan en las construcciones romanas a partir del siglo III d. C.
} 
El tipo de horno responde a la clase más frecuente documentada en Galicia, de planta rectangular, con arcos construidos en ladrillo para el soporte de la parrilla (como mencionamos anteriormente, desconocemos la forma de la cubierta). Hornos de similares características se han documentado en Lugo (en el Palacio de la Diputación y en la Plaza de Ferrol) y en Caldas de Reis (Naveiro 1991), o ejemplos portugueses como los de Aveiro (Almeida et al. 1987), Ponte de Lima (Almeida et al. 1992), o el de Ponte Louredo (Coelho et al. 1981-82).

Al igual que en otros casos, el horno aparece de forma aislada, sin que se hayan identificado ningún otro tipo de estructuras constructivas asociadas. Parece pues que nos encontramos ante un horno rural, aunque suponemos que estaría integrado en algún tipo de estructura de carácter agropecuario de mayor envergadura tipo villa, probablemente este tipo de talleres formarían parte de villae rusticas, en donde debía existir una clara disociación entre zonas residenciales y productivas (Naveiro 1991).

En las inmediaciones del horno, a escasa distancia se han documentado numerosos restos de época romana de distinta índole, como es el caso del yacimiento de O Mato, a 1,2 Km al sur, en el que se han recuperado tégulas, cerámica común, ladrillos..., que podrían indicarnos la presencia de un asentamiento tipo villa. Igualmente, en el ayuntamiento de Bueu se encuentran los yacimientos de San Martiño de Bueu (alfar y horno) y la posible villa de Pesqueira.

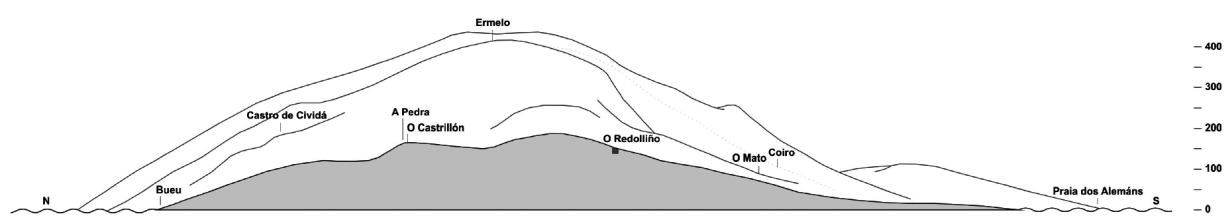

Figura 15: Perfil topográfico N-S del paso de A Portela con los principales yacimientos del entorno.

Normalmente este tipo de estructuras se encontraban próximas a lugares de extracción da materia prima (a menos de 2,5 km en dirección NW aparece el topónimo Fonte de Barro, que podría ser indicador de la presencia de este producto).

Por lo que respecta al emplazamiento conviene destacar su clara vinculación con el paso de A Portela, vía de tránsito natural N-S en el extremo más occidental de la península del Morrazo.

En conclusión, valorando las características del horno y tras un análisis de los materiales constructivos documentados y a la espera de la realización de analíticas de C-14 (de la tierra carbonizada del praefurnium) que precisen su cronología, 
parece que nos encontramos ante los restos de un horno de época romana tardía, entre los siglos III- V d. C.

\section{BIBLIOGRAFÍA}

ABOAL FERNÁNDEZ, R. y CASTRO HIERRO, V. 2005. Romanidade tardía: O Redolliño. En Criado y Cabrejas (Coord.). Obras Públicas e Patrimonio: Estudo arqueolóxico do Corredor do Morrazo. TAPA 35, 81-83. Santiago: IEGPS, CSIC-XuGa.

ALMEIDA, CARLOS A. BROCHADO DE; VIANA ANTUNES, J. M.; CARVALHO E SOUSA, M.J.; CAVALHEIRO DA CUNHA, R.M. 1992. O forno ceramico da Correlha-Ponte de Lima. Revista da Facultade de Letras. Historia II, Serie IX: 481-506. Porto.

ALMEIDA, CARLOS A. BROCHADO DE, ALMEIDA, ARTUR JORGE LEITE DE; LEAL, ANTONIO J. DA CUNHA. 1987. O forno cerámico romano do Eixo-Aveiro. Portugalia. Nova serie- Vol VIII: 69-72. Porto.

BERMÚDEZ MEDEL, A. 1987. Interés, problemática y metodología del estudio del material de construcción de tipo cerámico en la arquitectura romana de Tarraco. En Actas del XVIII Congreso Nacional de Arqueología (Zaragoza, 1987). Zaragoza: Secretaría General de Congresos Arqueológicos Nacionales.

COELHO, A.; LOPES, A. B.; TUNA, H. 1981-82. O forno cerámico de Louredo (Santa Marta de Peñaguiao). Portugalia. Nova Serie- Vol II/III: 149-152. Porto.

CRIADO BOADO, F. Y CABREJAS DOMÍNGUEZ, E (Coord). 2005. Obras Públicas e Patrimonio: Estudo arqueolóxico do Corredor do Morrazo. TAPA 35. Santiago: IEGPS, CSIC-XuGa.

LAGOSTENA BARRIOS, L Y BERNAL CASASOLA, D. 2006. Alfares y producciones cerámicas en la provincia de Cádiz. Balance y perspectivas. FIGLINAE BAETICA. Talleres alfareros y producciones cerámicas en la Bética romana (ss II a. C-VII d. C). Vol I: 39-124. Oxford. BAR International Series 1266. Universidad de Cádiz.

NAVEIRO LÓPEZ, J. L. 1991. El comercio antiguo en el NW peninsular. Monografías Urxentes do Museu. N ${ }^{\circ}$. A Coruña: Museu Arqueolóxico.

PARCERO OUBIÑA, C.; MÉNDEZ FERNÁNDEZ, F. Y BLANCO ROTEA, R. 1999. El registro de la información en intervenciones arqueológicas. Col. CAPA, 9. Santiago de Compostela: LAFC, Universidade de Santiago.

PÉREZ LOSADA, F. 1992. Contribución ó estudio da cerámica de construcción na Galicia romana. En Galicia da Romanidade á Xermanización. Actas do encontro científico en homenaxe a Fermín Bouza Brey, 241-261. Museo do Pobo Galego. Santiago de Compostela. 